\title{
La hiperfragmentación informativa en el Diseño Periodístico Impreso: propuesta metodológica y análisis de repercusiones cognitivas
}

\section{Information hyper-fragmentation in Print News Design: methodological proposal and analysis of cognitive effects}

Fernando Suárez Carballo

Profesor encargado de cátedra de la Facultad de Comunicación de la UPSA

(Universidad Pontificia de Salamanca)

Juan Ramón Martín San Román

Profesor encargado de cátedra de la Facultad de Comunicación de la UPSA

(Universidad Pontificia de Salamanca)

\section{Javier Nó Sánchez}

Decano Adjunto Comunicación y Educación Universidad Loyola Andalucía (Universidad Loyola Andalucía)

Fecha de recepción: 18 de septiembre de 2013

Fecha de revisión: 03 de enero de 2014

Para citar este artículo: Suárez Carballo, F., Martín San Román, J.R. y Nó Sánchez, J. (2014): La hiperfragmentación informativa en el Diseño Periodístico Impreso: propuesta metodológica y análisis de repercusiones cognitivas, Icono 14, volumen (12), pp. 63-104. doi: 10.7195/ri14.v12i1.627 


\section{Resumen}

Debido a la confluencia de varios factores, entre los que sobresale la enorme competencia en un nuevo contexto de comunicación dirigido por Internet, surge en la prensa escrita el fenómeno de la denominada hiperfragmentación informativa, que, mediante la disección del contenido en piezas más pequeñas, intenta potenciar la atención del lector y facilitar su lectura. En un intento por medir objetivamente la eficacia de determinados criterios de diseño gráfico, el estudio está orientado a evaluar la repercusión de los dos principios visuales que sustentan este modelo (la Fragmentación y el Contraste) en el comportamiento del lector y en sus procesos cognitivos (atención selectiva y comprensión). Para lograr estos objetivos, la investigación propone un método para la traducción de la página del diario a partir de los presupuestos del lenguaje de la imagen y el análisis de los elementos tipográficos que la conforman.

\section{Palabras clave}

Diseño gráfico - Diseño periodístico - Tipografía - Sintaxis visual - Percepción - Cognición Eficacia

\section{Abstract}

Due to the confluence of several factors, especially the hard competition in a new communication context leaded by Internet, the press experiences the appearance of the phenomenon called information hyper-fragmentation, which, by dividing the content into smaller pieces, try to enhance the reader's attention and readability. In an attempt to objectively measure the effectiveness of certain graphic design criteria, this study aims to evaluate the impact of two visual principles that describe this model (Fragmentation and Contrast) in the behavior of the reader and his cognitive processing (selective attention and comprehension). In order to achieve these objetives, the research offers a method to translate the newspaper page through the fundamentals of the visual literacy and the analysis of the typographical elements that build it.

\section{Key Words}

Graphic Design - News design - Typography - Visual literacy - Perception - Cognition Effectiveness 


\section{Introducción}

El Diseño Periodístico Impreso (DPI) ${ }^{1}$, concebido como “la interpretación del mensaje informativo bajo criterios funcionales de legibilidad, proporción, periodicidad, estilo y economía del medio donde se desarrolle" (Pérez Cuadrado y González Díez, 2001: 38), constituye una parte inherente a la estrategia del diario, cuya actividad compromete de forma decisiva en todas sus parcelas, resulta esencial en su proceso de comunicación y posee una responsabilidad crucial en la definición de su planteamiento global (Suárez Carballo, 2008).

Como mensaje visual intencional $\mathrm{y}$, por tanto, pieza integrante de esa macrodisciplina heterogénea que es el diseño gráfico, uno de los objetivos inmediatos del DPI apunta a la funcionalidad, probablemente su criterio más definitorio y determinante. En este sentido, y atendiendo a la definición anterior, una de las necesidades prioritarias consiste en observar en qué medida el componente formal puede potenciar la eficacia en la transmisión de la información del medio impreso. Según Contreras y San Nicolás, “el diseño periodístico cumple sobre todos los demás un objetivo central: la comunicación. Ello confiere al diseño un valor esencial que consiste en facilitar la comunicación de sus mensajes, y hacerlo con la velocidad y facilidad que impone el día a día" (2001: 61).

El diseño de diarios es organizar la información de forma que el lector discurra sobre ella de la forma más clara, directa y eficaz sin percibir que ha sido ordenada para su comprensión. El añadir motivaciones estéticas o hacerlas primar por encima de este hecho consustancial es desvirtuar y oscurecer la noticia (Lallana, 2000: 15).

Atendiendo a esa motivación fundamental, y a raíz de la interacción de diferentes factores (las bondades tecnológicas, la competencia de nuevos medios de comunicación, la configuración de un nuevo perfil de lector o las influencias estéticas contemporáneas), irrumpe el concepto de prensa de servicios, término incorporado por varios autores para definir un modelo cuya identidad está basada en "el rigor y la facilidad de lectura, en la veracidad y en los temas amenos; en la precisión y en los títulos atractivos. Contiene textos cortos, gráficos informativos

DOI: ri14.v12i1.627 | ISSN: 1697-8293 | Año 2014 Volumen 12 Nº 1 | ICONO14 
(infografismo), fotografías de calidad en color no exentas de intención y contenido $\mathrm{y}$, en definitiva, una información presentada con claridad y amenidad visual" (Casasús, 1995: 62). En un momento actual en el que, como señala Costa Sánchez (2013) atendiendo a los datos de la encuesta Navegantes en la Red de AIMC (2013), un gran porcentaje de usuarios (47\%) lee la prensa en sus dos ediciones (impresa y electrónica) o únicamente en su versión online $(37,7 \%)$, esta realidad cultural, sociológica y comunicativa podrían estar en el origen de estas tendencias:

Con el cambio de diseño, iniciado a finales de los ochenta, comenzó un largo camino hacia un modelo postelevisivo, que tiene su objetivo en la captación de la atención de un lector-tipo que dedica poco tiempo al periódico y que ya conoce buena parte de las informaciones por la radio, por la televisión $y$, en los últimos años, a través de Internet (López García, 2000: 5).

La correspondencia formal de este tipo de prensa está descrita por la denominada hiperfragmentación informativa, fórmula fundamentada en la apuesta por un número moderadamente alto de unidades formales diferenciadas dentro de la página y que acude a la fragmentación y el contraste como factores visuales principales. Como apuntaba Rom (2002: 100), “a principios del siglo XXI, parece que el desarrollo de las publicaciones electrónicas en Internet facilitará el aumento de la fragmentación visual de los diarios en unidades de información más pequeñas".

La diversificación de los elementos es otro de los medios para huir de la confección gris y monótona. La noticia se trocea en múltiples unidades que facilitan los distintos ritmos de lectura, permiten ofrecer diferentes aspectos del contenido o presentan la visión de los hechos desde diversas ópticas (Armentia Vizuete et al., 2001: 170).

Junto a esta técnica de la fragmentación, el principio de contraste contribuye a enfatizar el paradigma de lectura a varias velocidades propio de las nuevas estrategias de los medios impresos:

La cara externa de los periódicos se ha adecuado a las necesidades 
de la sociedad actual. Diagramación más atractiva, aumento de cuerpos e interlineas, fotografías de mayor tamaño y espectacularidad, despieces, color, infografías y hasta un lenguaje periodístico más conciso, que propicia dos tipos de lecturas: una rápida para lectores con prisa y otra en profundidad para quienes demandan una información más analítica. Son periódicos concebidos no solo para ser leídos, sino también para ser vistos; diarios en los que los lectores son simultáneamente espectadores (Álvarez Marcos, 1999:124).

El origen de la investigación se centra, precisamente, en la evaluación de la capacidad funcional de ambos atributos (Fragmentación y Contraste) dentro del diario, como factores esenciales del Diseño Periodístico Impreso (y del periodismo de servicio, en particular), y en su repercusión en el comportamiento del lector. De esta forma, el esquema de la investigación se estructura en dos bloques fundamentales:

- Una definición del "Modelo de repercusiones cognitivas de la hiperfragmentación informativa", como paradigma visual predominante de la prensa de servicios. Se trata de una propuesta teórica acerca de la incidencia de los factores que definen este modelo (Fragmentación y Contraste) en el consumo informativo del lector y en sus procesos mentales.

- Una investigación empírica, tomando como referencias los postulados del modelo teórico anterior, que tratará de observar científicamente la repercusión de los mencionados factores visuales en el procesamiento de información.

\section{Metodología}

\subsection{Modelo teórico de repercusiones cognitivas de la hiperfrag- mentación informativa}

Tal y como se desarrolla a continuación, el planteamiento empírico deber partir necesariamente de la consideración de dos vertientes fundamentales, 
que coinciden con los factores plástico o representacional y cognitivo o mental, y que, se intuye, afectarían al proceso de adquisición de información por parte del lector:

- Condicionantes intrínsecos: Relativos al propio sujeto y a los mecanismos cognitivos que determinan su forma de adquirir la información.

- Condicionantes extrínsecos: Relativos al planteamiento formal de la página impresa, a partir de los fundamentos básicos de la Teoría de la Imagen.

\subsubsection{Condicionantes intrínsecos: los procesos cognitivos}

El presente estudio contempla y evalúa la eficacia del Diseño Periodístico Impreso desde dos ángulos principales, considerados comúnmente como dos de las funciones más relevantes del diseño en la transmisión y en la recepción activa, constructiva e interpretativa de la información en el diario: la focalización o atención selectiva y la comprensión. Una tercera (el recuerdo) intervendría como el instrumento de medición de ambas.

\subsubsection{La focalización}

Es el criterio que corresponde a la atención selectiva (o preferencia hacia determinados elementos dentro de la superficie impresa), un "realce sobre una clase de objetos o eventos percibidos en preferencia a otros" (Kahnemann, 1997: 133). Desde la perspectiva del lenguaje visual del diario, se interpreta que los atributos gráficos de los diferentes elementos individuales que integran la página de un periódico determinan un interés prioritario del lector hacia determinadas zonas de esta superficie y hacia determinadas unidades formales que, de esta forma, adquieren prioridad de lectura y son procesadas de forma más eficiente y permanente que el resto.

Se trata de averiguar, pues, cuáles son los atributos visuales más decisivos en la preferencia por determinados elementos en la página, que pueden contribuir a la mayor rentabilidad en la jerarquización de los contenidos. 
El procesador humano no es, en consecuencia, un receptor pasivo dirigido por los datos (...), sino que "selecciona", decide qué aspectos del entorno requieren una elaboración cognitiva prioritaria en un modo de funcionamiento más controlado y más vinculado a lo que se ha convenido en llamar actividad consciente (Roselló, 1997: 29).

\subsubsection{La comprensión}

Una de las cualidades que se atribuyen tradicionalmente a la forma periodística es su capacidad para facilitar y optimizar la transmisión y consiguiente percepción y adquisición de la información. En este sentido, determinados factores visuales y propuestas compositivas deberían poder controlar el procesamiento del material informativo de la página.

La comprensión, asimismo, está determinada de forma directa por la atención selectiva; es decir, el resultado de la preferencia por los diferentes elementos individuales de la página y del itinerario resultante derivaría en un determinado nivel de percepción de la información. Se prevé, en esta línea, que una composición visual concreta pueda facilitar el recorrido visual de la página y, por tanto, potenciar la huella memorística y la asimilación del material informativo, globalmente.

La comprensión se interpreta, además, como un resultado de la atención sostenida o vigilancia del sujeto, esto es, la capacidad de este para mantener la atención durante determinados períodos de tiempo, más o menos amplios, y un resultado inmediato de su capacidad de concentración (o atención centrada). Para Puente Ferreras (1998: 214), en este sentido, "un organismo vigilante es aquel que 'presta atención' a tareas que son monótonas y de larga duración".

Desde esta perspectiva, en tanto que "un proceso cognitivo de alto nivel, que requiere la intervención de los sistemas de memoria y atencionales, de los procesos de codificación y percepción y, en fin, de operaciones inferenciales basadas en los conocimientos previos y en sutiles factores contextuales" (De Vega, 1997: 367), mediante el concepto de comprensión se intenta evaluar el volumen total de la información del relato adquirida y procesada eficientemen-

DOI: ri14.v12i1.627 | ISSN: 1697-8293 | Año 2014 Volumen 12 № 1 | ICONO14 
te por el sujeto, mientras que la focalización se ocuparía del rendimiento sobre sus partes constitutivas.

\subsubsection{El recuerdo}

Junto a otros instrumentos conductuales (movimientos oculares o eye tracker, por ejemplo) o psicofisiológicos (evaluación del tamaño de la pupila o tasa cardiaca), uno de los índices empleados tradicionalmente para la cuantificación tanto de la atención selectiva como de la comprensión ha sido la memoria o el grado de recuerdo de la información, englobados dentro de las tareas de rendimiento (Botella, 1999).

En el análisis de la focalización, el recuerdo de determinados items se interpreta como el resultado de su selección prioritaria frente a los restantes. En estos índices, las propiedades visuales de los elementos (en los que se centra el estudio) desempeñarían un papel fundamental en la preferencia de lectura por parte del sujeto ${ }^{2}$.

En relación a la comprensión global del estímulo, el volumen de items almacenados resultaría de la capacidad para mantener una atención más prolongada (atención sostenida) y de un mejor procesamiento de la información integrada en la página, globalmente. Desde esta perspectiva, pues, la memoria se erige en la variable fundamental de la preferencia del sujeto (a través de los elementos particulares que es capaz de discriminar y recuperar posteriormente) y de la comprensión global, definida como la cantidad total de información que el sujeto es capaz de procesar y recordar en un margen de tiempo determinado.

En esta línea, Elosúa (2000: 10-11) propone una interacción entre los conceptos de memoria, aprendizaje y comprensión, estrechamente relacionados e interdependientes:

En efecto, una buena comprensión, además de facilitar la recuperación posterior del contenido a partir de la memoria, o mejor dicho -y para que se vea mejor la relación intrínseca de nuevo- al mismo tiempo que lo hace consigue igualmente un claro aprendizaje. Mien- 
tras que cuando no se da una comprensión habrá una recuperación pobre de dicha información en la memoria que se pondrá de manifiesto en un aprendizaje que no será claro ni consciente a lo largo del tiempo.

La memoria, entonces, participaría activamente en la metodología experimental de la comprensión, en tanto que un "proceso interactivo que implica la construcción mental acerca del significado global del discurso, algo que se ha puesto claramente de manifiesto en las medidas de recuerdo" (Gutiérrez et al., 1999: 15).

Este modelo aborda la evaluación de las repercusiones mnésicas a través de la memoria explícita o declarativa. Esta técnica alude a un tarea de memoria consciente y manifiesta, en la cual los conocimientos son expresados de forma directa; esto es, se trata de una memoria que almacena contenidos informativos y que puede declararse (Crespo, 2002). Para ello, se recurre a una prueba (test) de reconocimiento para tratar de constatar el nivel de recuerdo y las posibilidades de recuperación de forma voluntaria, cualitativamente (tipo de respuestas correctas) y cuantitativamente (número de respuestas correctas).

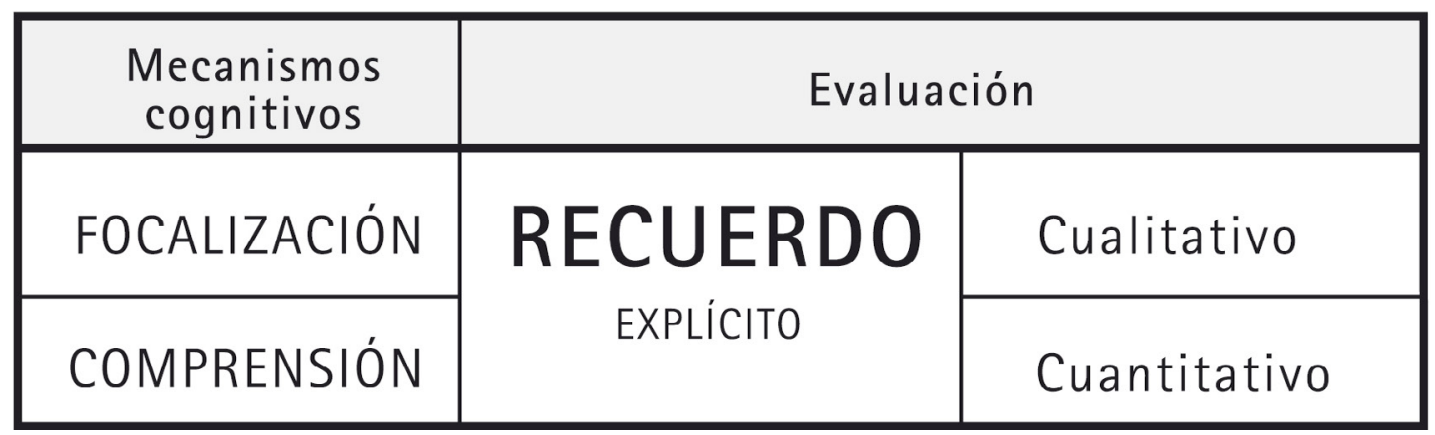

Figura 1: Mecanismos cognitivos y metodología de evaluación 


\subsubsection{Condicionantes extrínsecos: el código visual de la página}

Este modelo visual de hiperfragmentación informativa se ha descrito a partir de la multiplicidad de opciones, ritmos y secuencias de lectura que genera la ruptura del texto lineal tradicional, por la inclusión de numerosos focos de atención que condicionan el recorrido visual de la página y por la apuesta por una estructuración y distribución del contenido más dinámica, ágil y visual, que surge de dos criterios visuales (Fragmentación y Contraste), los cuales, a su vez, dan lugar a una composición quebrada, asimétrica y con una marcada jerarquía, derivada de los focos de atención descritos.

Para la evaluación de la eficacia de la fórmula visual de este modelo, se hace necesaria una traducción minuciosa de la página impresa al lenguaje de la imagen, siempre en aras a describir los dos objetivos expuestos (focalización y comprensión).

\subsubsection{Elementos visuales de la página: microformas, formas, macroformas}

Para diseccionar e interpretar visualmente la página del diario, y para determinar el número de elementos que la conforman, este estudio recupera la división tradicional que establecen los criterios de sintaxis visual del Diseño Periodístico Impreso y las normas de agrupamiento visual de la escuela de la Gestalt (Aparici et al., 1992; Costa, 1998; Gubern, 1992; Köhler, 1972; Moles, 1991; entre otros) y se apoya en las propuestas metodológicas de Tena (1999) para distinguir los siguientes tres bloques de elementos, que difieren en su distinto grado de autonomía semántica3:

1. Microformas: Caracteres (elementos básicos) y palabras (que surgen de la combinación de los signos alfabéticos y no alfabéticos individuales).

2. Formas: Elementos redaccionales o divisiones internas de la noticia, que se obtienen como resultado de la aplicación de las reglas gestálticas de agrupamiento a las microformas, que están definidas por atributos visuales concretos y particulares y que poseen una elevada capacidad semántica (por ejemplo, titulares principales, entradillas, sumarios, ladillos, despieces o cuerpo de texto $)^{4}$. 
3. Macroformas: Son las noticias, unidades íntegras de información que también están conformadas a partir de las leyes de agrupamiento, aplicadas sobre las citadas formas.

\begin{tabular}{|c|c|}
\hline \multicolumn{2}{|c|}{ ELEMENTOS } \\
\hline Nivel visual & Nivel redaccional \\
\hline Microformas & Caracteres, palabras \\
\hline Formas & Unidades \\
\hline Macrofoccionales \\
\hline Página impresa \\
\hline
\end{tabular}

Figura 2: Elementos visuales y redaccionales en función de su autonomía semántica

\subsubsection{Categorías visuales básicas}

A continuación se enumeran y describen de forma exhaustiva cinco categorías visuales que permiten describir objetivamente los anteriores elementos, así como justificar la presencia y la envergadura de los factores de Fragmentación y Contraste Global en la página impresa. La lógica de estas categorías se basa en una simplificación más operativa del conjunto de elementos básicos y leyes sintácticas desarrolladas por la Teoría de la Imagen (Dondis, 1976; Groupe $\mu$, 1993; Villafañe y Mínguez, 2000; entre otros). En ellas, se reúnen conceptos como forma, color, tamaño, textura, dirección o tamaño, entre otras. 
La exhaustiva definición y operacionalización de estas categorías permitirán, asimismo, determinar en cada momento la eficacia de estas en determinados procesos cognitivos, como la focalización, el recuerdo o la comprensión.

\section{a. Cantidad}

Consiste en la cuantificación de las formas autónomas presentes en la página. La agrupación de las microformas en formas se efectúa a través de los criterios de relación de unidades incorporados por la psicología Gestalt, que están intimamente vinculados a algunas de las variables contempladas por el objeto de estudio (como el Aspecto o la Posición).

\section{b. Posición}

Diferentes estudios avalan la relevancia de la Posición en la atención selectiva, en el comportamiento y recorrido de la mirada en la página impresa y en el procesamiento de la información de las diferentes formas que la constituyen.

La Posición constituye un elemento de gran relevancia en la definición del Modelo de hiperfragmentación informativa, en la medida en que permite potenciar el contraste entre las diferentes formas de la página y resulta esencial en la ruptura o interrupción del proceso de lectura. Para concretar e identificar la ubicación de los diferentes elementos en la composición, se hace necesaria una estructuración modular de la página impresa a través de una retícula flexible que permita la división homogénea de esta en varias zonas diferenciadas.

\section{c. Tamaño}

Está vinculado al nivel escalar de las formas, y se describe como la cantidad de superficie total ocupada por una unidad formal diferenciada. Su unidad de medida es el módulo, que deriva de la mencionada estructuración reticular de la página.

El Tamaño posee una importante significación visual, en cuanto actúa como indicador de la jerarquía (o de la relevancia visual atribuida a cada elemento) y de la focalización compositiva, y posee gran incidencia en la definición del Contraste, como se especifica a continuación ${ }^{5}$.

ICONO14 | Año 2014 Volumen 12 № 1 | ISSN: 1697-8293 | DOI: ri14.v12i1.627 


\section{d. Aspecto}

La página impresa está configurada por diferentes estructuras informativas (formas): elementos tipográficos, elementos gráficos (fotografía, ilustración) y elementos infográficos, tipología desarrollada por West (1991) a partir de sus diferentes niveles de iconicidad (Moles, 1991). No obstante, como se ha mencionado, de cara a evitar la posible intromisión de variables ajenas a la investigación que pudieran desvirtuar el objeto de estudio o de limitar su valor científico, el modelo pretende un acercamiento al fenómeno de la hiperfragmentación informativa únicamente a través de la evaluación de elementos tipográficos. Serán, por tanto, variaciones en los atributos formales de las microformas y formas tipográficas presentes en la página los que determinen el aspecto de estos elementos. Estos rasgos tipográficos son el cuerpo, la familia tipográfica, las variantes tipográficas (figura, ojo, caja, tamaño), la alineación tipográfica y el color o textura. La síntesis de estas subcategorías tipográficas derivan en un determinado Aspecto individual de las microformas presentes en la página.

\section{e. Contraste Individual (CI)}

Según el presente modelo teórico, existiría un último concepto resultante de la combinación de las categorías visuales de Tamaño y Aspecto, que contribuye a definir de forma más exacta el grado de diferenciación total de un elemento particular y que, además, permite una descripción del nivel de hiperfragmentación informativa de una página impresa a partir no solo de la Cantidad total de elementos, sino asimismo de la desviación del Aspecto de estas formas y de su intensidad. Por tanto, para una correcta interpretación de esta diferenciación, no sólo es preciso considerar los rasgos formales de un elemento concreto, sino también el grado de originalidad o frecuencia, que tiene su lógica en la categoría de Tamaño. En esta puntualización encuentra su sentido el concepto de Contraste.

En definitiva, el Contraste Individual (CI) de un elemento dado podría definirse como su "grado de diferenciación formal (Aspecto) en relación a los atributos visuales más comunes de la página (el Aspecto mayoritario), teniendo en cuenta la superficie ocupada (el Tamaño relativo)".

DOI: ri14.v12i1.627 | ISSN: 1697-8293 | Año 2014 Volumen 12 Nº 1 | ICONO14 
El tratamiento y valoración de cada una de las categorías designadas, en relación a los diferentes niveles de unidades formales de la página, es el siguiente:

\begin{tabular}{|l|l|c|}
\hline \multicolumn{1}{|c|}{ Categoría } & \multicolumn{1}{|c|}{ Descripción } & Elemento Fundamental \\
\hline Cantidad & $\begin{array}{l}\text { Número de formas diferenciadas y autónomas } \\
\text { (elementos redaccionales) presentes en la pá- } \\
\text { gina }\end{array}$ & Forma \\
\hline Posición & $\begin{array}{l}\text { Ubicación de cada una de las formas en la pá- } \\
\text { gina }\end{array}$ & Forma \\
\hline \multirow{2}{*}{ Tamaño } & $\begin{array}{l}\text { Superficie ocupada por cada una de las formas } \\
\text { (número de módulos que determinan su exten- } \\
\text { sión) }\end{array}$ & Forma \\
\hline \multirow{2}{*}{ Aspecto } & $\begin{array}{l}\text { Atributos tipográficos de las unidades formales } \\
\text { (familia, cuerpo, variante, alineación) }\end{array}$ & Microforma \\
\cline { 2 - 4 } & Tono y textura de las formas (tramas) & Forma \\
\hline \multirow{2}{*}{ Contraste Individual } & $\begin{array}{l}\text { Diferenciación formal del elemento en relación } \\
\text { a la cantidad de superficie ocupada }\end{array}$ & Forma \\
\hline
\end{tabular}

Tabla 1. Categorías visuales y relación con los elementos básicos

\subsubsection{Factores visuales}

La lógica de las cinco categorías básicas anteriores reside en la necesidad de describir exhaustivamente el modelo y de traducir la página impresa al lenguaje visual, con especial hincapié en los dos factores visuales básicos que se pretenden evaluar:

\section{a. Fragmentación}

A través de las leyes de agrupamiento originadas por la psicología Gestalt, es posible aislar e individualizar diferentes elementos dentro de la página (descritos como formas), que tienen asignada una serie de funciones concretas dentro de esta superficie y adquieren desigual relevancia.

Cuando, a través de la incorporación de estas formas, se produce una ruptura y distribución de la información en varias de estas unidades, $y$, por consiguiente, se interrumpe de la secuencialidad de lectura, se produce el fenómeno definido como Fragmentación, esto es, la “descomposición de la página en unidades informativas 
diferentes y autónomas, complementarias e interrelacionadas entre sí". Está, por tanto, ligado al concepto de profusión, sinónimo de un planteamiento visual que, derivado de esta ruptura, permite el aislamiento de un elevado volumen de formas.

La variable de Cantidad, concretada en el número de unidades formales diferenciadas presentes en la página, es el criterio fundamental en la definición de este atributo.

\section{b. Contraste Global (CG)}

Para la correcta diferenciación de los distintos bloques que conforman la página, se hace imprescindible una variación evidente y acentuada de las propiedades formales de estos en el contexto en el que tienen lugar. El Contraste Global se puede definir como la "disparidad o variación visual (cromática, formal, tonal o textural) generada por las diferentes formas que intervienen en una superficie determinada" (en este caso, la página impresa) o, como se ha indicado, "el grado de desviación formal del conjunto de elementos visuales de la página en relación al Aspecto mayoritario, teniendo en cuenta la superficie parcial ocupada por cada uno de ellos".

Por tanto, haciendo uso de las variables establecidas anteriormente, este concepto permite definir el nivel de variación o complejidad formal de una página, así como una mejor definición de la distancia formal de las unidades individuales, lo que contribuye a explicar de forma más precisa la lógica de la focalización informativa.

En la fórmula visual de la hiperfragmentación informativa resulta prácticamente imposible desvincular las variables de Fragmentación y Contraste. Mientras el Contraste significa, en mayor o menor medida, una jerarquización visual de la página y una ruptura de la secuencialidad, la Fragmentación debe apoyarse necesariamente en el Contraste para potenciar la división y la singularidad de los diferentes elementos de la página.

\subsubsection{Intervención de la hiperfragmentación en los mecanismos cognitivos}

Una vez traducido el Modelo de hiperfragmentación al lenguaje visual en diferentes niveles, su acción en la página y en los mecanismos cognitivos del sujeto

DOI: ri14.v12i1.627 | ISSN: 1697-8293 | Año 2014 Volumen 12 № 1 | ICONO14 
serían los siguientes:

- La selección, distribución, definición y estructuración de las microformas y formas a partir de las cinco categorías visuales básicas deriva en la descripción de los factores visuales de Fragmentación y Contraste de la página (definitorios, en un determinado nivel, del Modelo de hiperfragmentación informativa).

- El planteamiento compositivo resultante de los diferentes niveles adoptados por los factores visuales de Fragmentación y Contraste Global determina la focalización en la página impresa de los diferentes elementos, descritos individualmente a partir de las categorías visuales de Aspecto, Tamaño, Contraste y Posición.

- Los factores visuales de Fragmentación y Contraste influyen en el mantenimiento de la capacidad atencional del sujeto (atención sostenida) y en la comprensión global del contenido informativo; en otras palabras, el recuerdo cuantitativo está condicionado por los diferentes niveles de Fragmentación y Contraste de la página.

\subsubsection{Representación visual del modelo}

A continuación se representa gráficamente el Modelo de repercusiones cognitivas de la hiperfragmentación informativa, que se pretende contrastar empíricamente. Se trata de una síntesis de cada uno de los elementos formales y cognitivos que intervienen en la formulación de este paradigma.

El cuadro refleja dos niveles claramente diferenciados, correspondientes a los dos grandes bloques que constituyen el objeto de estudio: los condicionantes extrínsecos, relativos al planteamiento formal de la página (Diseño Periodístico Impreso) y los condicionantes intrínsecos, vinculados a los mecanismos cognitivos del lector.

Figura 3: Representación visual del Modelo de repercusiones cognitivas de la hiperfragmentación informativa 


\section{DPI}

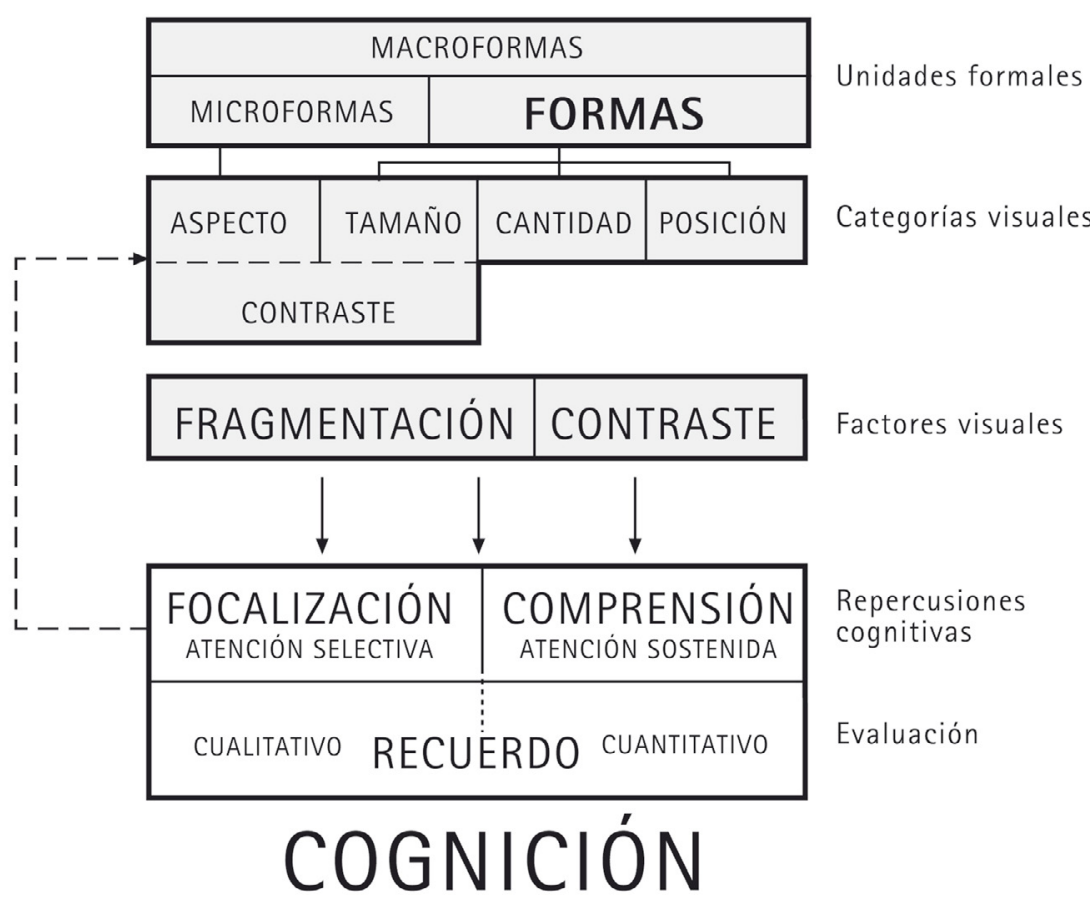

\subsection{Trabajo de campo: contrastación empírica del modelo}

Esta fase del trabajo pretende contrastar la validez del modelo desarrollado en el anterior apartado. En otras palabras, se intenta observar la intervención de los factores de Fragmentación y Contraste en los mecanismos cognitivos y, en definitiva, explicar el comportamiento del receptor en función del planteamiento formal de la página, que está definido por estas variables.

\subsubsection{Objetivos de la investigación}

La investigación se fundamenta en los siguientes cinco objetivos:

1. Construir, analizar y definir la página impresa de un diario conforme a postulados exclusivamente formales, basados en el lenguaje visual.

2. Extraer, a partir de la definición previa de una serie de cinco categorías vi- 
suales básicas recogidas de la Teoría de la Imagen, un conjunto de dos principios formales que conforman de manera decisiva el Modelo de hiperfragmentación informativa (cuya eficacia se pretende evaluar), y que se prevén esenciales en la percepción del receptor: el Contraste y la Fragmentación.

3. Observar si estas especificidades formales son capaces de modificar la percepción de la página impresa por parte del lector, desde dos criterios fundamentales: selección (focalización o atención selectiva) y comprensión global (basada en la cantidad total de información adquirida), evaluados a través de la memoria a largo plazo.

4. Analizar si existe una correlación entre los criterios formales y el procesamiento final de la información por parte del lector; es decir, en qué grado los factores visuales son determinantes en la transmisión y en la comprensión de un determinado contenido.

5. Descubrir el alcance de cada una de las categorías visuales iniciales (Aspecto, Tamaño, Contraste Individual, Posición, Cantidad), que describen la página impresa (y cada uno de sus elementos integrantes), en la recepción de la información, atendiendo al grado de Fragmentación y Contraste Global de la página.

\subsubsection{Hipótesis de la investigación}

La investigación propone las siguientes hipótesis de trabajo:

\subsubsection{Hipótesis general}

“El Diseño Periodístico Impreso determina la percepción de la página impresa por parte del lector e influye en sus mecanismos cognitivos de atención selectiva, recuerdo y comprensión de la información".

La anterior hipótesis principal puede desglosarse en un segundo gran nivel de hipótesis generales, que parte de los dos factores visuales de Diseño Periodístico Impreso que se pretenden estudiar y de las dos consecuencias cognitivas propuestas, y que permite concretar los objetivos de la investigación: 
- Los factores visuales de Fragmentación y Contraste Global, unidos a los atributos visuales individuales de los elementos que integran la página, condicionan la atención selectiva (focalización) y el procesamiento de estos, evaluados a través de la cantidad o el grado de recuerdo de la información.

- Los factores visuales de Fragmentación y Contraste Global condicionan la comprensión del conjunto de la página impresa, evaluada a través de la cantidad o el grado de recuerdo de la información.

\subsubsection{Hipótesis específicas}

Las anteriores hipótesis principales pretenden contrastarse a partir de las siguientes hipótesis secundarias:

- Una composición visual basada en niveles intermedios de Fragmentación y Contraste Global contribuye a aumentar la cantidad de información retenida a largo plazo de la página impresa, frente a aquellos estímulos definidos por niveles altos y bajos de estos factores.

- Una composición visual basada en niveles bajos de Fragmentación y Contraste Global prioriza la linealidad de lectura de la página, a través de la Posición como categoría visual fundamental.

- Una composición visual basada en niveles intermedios de Fragmentación y Contraste Global prioriza las unidades formales con un Tamaño menor y una diferenciación formal mayor con respecto al Aspecto predominante en la página, y, en definitiva, con un Contraste Individual mayor.

- Una composición visual basada en niveles elevados de Fragmentación y Contraste Global potenciará la atención selectiva sobre los elementos con menor Tamaño y una diferenciación mayor (respecto al Aspecto mayoritario de la página), y, en definitiva, con un Contraste Individual mayor, pero producirá una mayor distribución y dispersión en el recuerdo de la información del conjunto de elementos. 
- El gradual aumento de la Fragmentación y el Contraste Global redundará en un incremento de la heterogeneidad en la respuesta de los sujetos y en una mayor disparidad de su preferencia hacia determinadas unidades dentro de la página.

\subsubsection{Operacionalización de variables}

Para la evaluación y posterior interpretación de las hipótesis, se hace necesaria una descripción y operacionalización exhaustivas de las variables que intervienen en ellas:

\subsubsection{Variables independientes: las categorías visuales}

Las integran las categorías de Cantidad, Tamaño, Aspecto, Posición y Contraste Individual, seleccionadas para evaluar el planteamiento formal global de la página $\mathrm{y}$ de los elementos que la describen.

\section{a. Cantidad}

Se define como el "número total de elementos de la página formalmente autónomos y diferenciados". Esta definición implica que, de cara a la cuantificación final, sean tenidos en cuenta aspectos como la parcelación de un mismo elemento en la página, el cual, a pesar de mantener atributos visuales homogéneos, pasa a ser contabilizado a partir del número de subdivisiones realizadas ${ }^{7}$.

\begin{tabular}{|c|l|c|}
\hline Variable independiente & \multicolumn{1}{|c|}{ Niveles } & Valores \\
\hline \multirow{4}{*}{ Cantidad } & 1: Baja & 1-10 els. \\
\cline { 2 - 3 } & 2: Medio-baja & $11-20$ els. \\
\cline { 2 - 3 } & 3: Medio-alta & 21-30 els. \\
\cline { 2 - 3 } & 4: Alta & 31-40 els. \\
\hline
\end{tabular}

Tabla 2: Valores de Cantidad (Fragmentación)

\section{b. Tamaño}

Se define como el "número de módulos derivados de la retícula base que posee 
una unidad formalmente autónoma y diferenciada". Teniendo en cuenta los atributos globales de los estímulos, la evaluación de esta variable se efectuará a partir de los siguientes niveles y valores:

\begin{tabular}{|c|l|c|}
\hline Variable independiente & \multicolumn{1}{|c|}{ Niveles } & Valores \\
\hline \multirow{4}{*}{ Tamaño } & 1: Tamaño Bajo & 1-6 módulos \\
\cline { 2 - 3 } & 2: Tamaño Medio & 7-17 módulos \\
\cline { 2 - 3 } & 3: Tamaño Alto & 18 módulos en adelante \\
\hline
\end{tabular}

Tabla 3: Valores de Tamaño

\section{c. Posición}

Se define como la "ubicación de un elemento en cualquiera de los cuatro cuadrantes principales en los que se divide la estructura reticular". La medición de esta variable se efectuará a partir de los siguientes niveles y valores ${ }^{8}$ :

\begin{tabular}{|c|l|c|}
\hline Variable independiente & \multicolumn{1}{|c|}{ Niveles } & Valores \\
\hline \multirow{4}{*}{ Posición } & 1: Primer cuadrante & Módulos A1-D10 \\
\cline { 2 - 3 } & 2: Segundo cuadrante & Módulos A10-D20 \\
\cline { 2 - 3 } & 3: Tercer cuadrante & Módulos E1-G10 \\
\cline { 2 - 3 } & 4: Cuarto cuadrante & Módulos E10-G20 \\
\hline
\end{tabular}

Tabla 4: Valores de Posición

\section{d. Aspecto}

Se define como el "grado de desviación formal de los atributos formales y tipográficos de los elementos en relación a las características visuales básicas de la página". Estas características visuales básicas de la página están representadas por "las características visuales que ocupan la superficie mayoritaria de la página".

La definición del Aspecto de los elementos de cada reactivo se construye a través de la consideración de una serie de atributos tipográficos, de los que son portadores, y de su ponderación, en función de la relevancia que se atribuye a estos elementos en su diferenciación con respecto a las características mayoritarias de la página: 
84 Fernando Suárez Carballo, Juan Ramón Martín San Román y Javier Nó Sánchez

\begin{tabular}{|c|c|c|c|}
\hline Subcategoría & Ponderación & Valores & Atributos \\
\hline \multirow{2}{*}{ Categoria tipográfica } & \multirow{2}{*}{0,05} & 1 & Romana antigua \\
\hline & & 2 & Palo seco \\
\hline \multirow{3}{*}{ Alineación } & \multirow{3}{*}{0,05} & 1 & Justificada \\
\hline & & 2 & Izquierda \\
\hline & & 3 & Centrada \\
\hline \multirow{3}{*}{$\begin{array}{c}\text { Variante } \\
\text { (grosor, cursiva, caja) }\end{array}$} & \multirow{3}{*}{0,2} & 1 & Mismas variantes \\
\hline & & 2 & Diferencia de 1 variante \\
\hline & & 3 & Diferencia de 2 variantes \\
\hline \multirow{3}{*}{ Cuerpo } & \multirow{3}{*}{0,4} & 1 & 9-12 pt. \\
\hline & & 2 & 13-18 pt. \\
\hline & & 3 & $19-50 \mathrm{pt}$. \\
\hline \multirow{3}{*}{ Trama } & \multirow{3}{*}{0,3} & 1 & Sin trama \\
\hline & & 2 & Trama de $10-20 \%$ de negro (positivo) \\
\hline & & 3 & Trama de $75-100 \%$ de negro (negativo) \\
\hline
\end{tabular}

Tabla 5: Ponderación de los criterios de Aspecto

A raíz del promedio de la suma ponderada de estos cinco atributos tipográficos, se define la variable global de Aspecto, que adopta los siguientes valores:

\begin{tabular}{|c|l|c|}
\hline Variable independiente & \multicolumn{1}{|c|}{ Niveles } & Valores \\
\hline \multirow{3}{*}{ Aspecto } & 1: Diferencia baja & $1.00-130$ \\
\cline { 2 - 3 } & 2: Diferencia media & $1.35-1.60$ \\
\cline { 2 - 3 } & 3: Diferencia alta & $1.65-3.00$ \\
\hline
\end{tabular}

Tabla 6: Valores de Aspecto

\section{e. Contraste (global e individual)}

La importancia del este último concepto, que se basa en algunas de las variables mencionadas, se explica por dos motivos fundamentales:

- Establece una síntesis entre las variables de Aspecto y Tamaño (Contraste Individual de cada elemento). Con ello, permite una mayor aproximación al concepto de "desviación visual" de una forma determinada dentro de la página. Además de tener presente la diferenciación formal propiamente 
dicha (Aspecto), considera la superficie ocupada (Tamaño) como un índice de la particularidad, originalidad o disimilitud en relación al planteamiento formal medio de la página.

Para medir el grado de Contraste Individual, se han extraído nueve posibilidades derivadas de la combinación de las variables de Tamaño y Aspecto, y se han agrupado en dos conjuntos fundamentales:

\begin{tabular}{|l|l|l|l|}
\hline & \multicolumn{1}{|c|}{ Aspecto 3 } & \multicolumn{1}{|c|}{ Aspecto 2 } & \multicolumn{1}{c|}{ Aspecto 1 } \\
\hline Tamaño 1 & 1: $\mathrm{T} 1 / \mathrm{A} 3$ & 4: T1/A2 & 7: T1/A1 \\
\hline Tamaño 2 & 2: $\mathrm{T} 2 / \mathrm{A} 3$ & 5: T2/A2 & 8: T2/A1 \\
\hline Tamaño 3 & 3: T3/A3 (sin valores) & 6: T3/A2 (sin valores) & 9: T3/A1 \\
\hline
\end{tabular}

Tabla 7: Diferentes posibilidades de Contraste Individual derivadas de la combinación de Tamaño y Aspecto

\begin{tabular}{|c|c|c|}
\hline Variable independiente & Categorías & Combinaciones \\
\hline \multirow{3}{*}{ Contraste individual (CI) } & Contraste alto (2) & $\begin{array}{c}\text { T1/A3, TI/A2, } \\
\text { T2/A3, T2/A2 }\end{array}$ \\
\cline { 2 - 3 } & Contraste bajo (1) & T1/A1, T2/A1, T3/A1 \\
\hline
\end{tabular}

Tabla 8: Valores de Contraste Individual, a partir de las combinaciones anteriores

- Permite valorar el grado de diferenciación formal del conjunto total de los elementos de la página -Contraste medio de la página o Contraste Global (CG)-, tomando como referencia los atributos formales mayoritarios y considerando, además del Aspecto individual, la superficie ocupada. Interesa a este estudio, fundamentalmente, como un sinónimo de la complejidad compositiva.

Para la obtención precisa del Contraste Global (CG) de la página, se recurre a la suma de las diferencias entre el Aspecto individual (A) de cada elemento y el Aspecto mayoritario $(\mathrm{Am})$, en relación a la superficie ocupada $(\mathrm{T}): \mathrm{CG}=\Sigma(\mathrm{A}-\mathrm{Am}) \mathrm{xT}$

Al igual que en el concepto de Cantidad, se antoja especialmente complicado estandarizar los valores de Contraste Global independientemente de los atributos 
de la página, debido a la multiplicidad de variables que intervienen en su definición. En este estudio, por tanto, las diferentes categorías corresponderán a los valores obtenidos en cada uno de los reactivos, que han sido diseñados ad hoc para enfatizar sus diferencias:

\begin{tabular}{|l|l|c|}
\hline Variable independiente & \multicolumn{1}{|c|}{ Categorias } & Valores \\
\hline \multirow{4}{*}{ Contraste Global } & 1: Baja & 0,12 \\
\cline { 2 - 3 } & 2: Medio-baja & 0,38 \\
\cline { 2 - 3 } & 3: Medio-alta & 0,52 \\
\cline { 2 - 3 } & 4: Alta & 0,61 \\
\hline
\end{tabular}

Tabla 9: Valores de Contraste Global

\subsubsection{Variable dependiente: el recuerdo}

La incidencia de los anteriores factores en la respuesta del lector se evalúa a través del grado de recuerdo de la información, que constituye la variable dependiente del estudio.

Como se indica a continuación, el nivel de recuerdo es evaluado a través de un test de reconocimiento, consistente en una tarea de memoria explícita a largo plazo. Esta prueba fue presentada de forma homogénea en los cuestionarios de cada uno de los cuatro diferentes estímulos.

Mediante la evaluación de los resultados de la prueba de recuerdo, se pretende responder a los dos grandes objetivos de la investigación:

\section{a. Atención selectiva o focalización}

Se pretende evaluar cuáles son las variables independientes que influyen de manera más decisiva en la atención selectiva de la información, esto es, cuáles son los atributos visuales más relevantes en la preferencia de lectura por determinados elementos.

La investigación, por tanto, mide la focalización en relación a los distintos atributos reflejados por las variables independientes en los siguientes términos: 
“Promedio de aciertos en el test de reconocimiento que reciben los diferentes niveles de cada una de las categorías visuales, previamente asociados a los distintos elementos formales de la página".

\section{b. Comprensión global}

Se pretende evaluar cómo la manipulación de las variables independientes es capaz de aumentar el recuerdo del volumen total de información de la página, que se establece como el resultado de la suma de los promedios de recuerdo derivado de la atención selectiva de los diferentes elementos de la página o la suma de respuestas correctas de las herramientas de recogida de datos.

El grado de comprensión del sujeto se interpreta como una consecuencia de la cantidad total de recuerdo del conjunto de elementos de la página procesados y recordados, $\mathrm{y}$, según esta definición, está vinculado a los niveles de concentración o atención sostenida de la página, a partir de la suma de las respuestas correctas del instrumento de recogida de datos.

En definitiva, la investigación mide la comprensión en los siguientes términos: "Promedio de aciertos resultante de la suma del total de respuestas correctas en las cuestiones integrantes del test de reconocimiento o prueba de memoria explícita."

\subsubsection{Metodología: el proceso de investigación}

Tras una breve primera fase, configurada por un experimento previo para intentar detectar posibles carencias de la investigación y corregirlas de cara a la elaboración del experimento final, el método para contrastar las hipótesis comprendió los siguientes pasos:

\subsubsection{Diseño de los estímulos (páginas de diario)}

Las páginas se confeccionaron de tal manera que pudieran potenciarse y cuantificarse los factores visuales de Contraste Global y Fragmentación, a partir de las cinco categorías básicas principales (Cantidad, Aspecto, Tamaño, Posición, Contraste Individual), cuya presencia en cada uno de los reactivos se intentó diversificar para efectuar una comparativa inter e intra-página.

DOI: ri14.v12i1.627 | ISSN: 1697-8293 | Año 2014 Volumen 12 Nº 1 | ICONO14 
Partiendo de las cinco categorías básicas mencionadas (Aspecto, Cantidad, Tamaño, Posición y Contraste Individual), y tomando como referencia los dos atributos básicos que definen el modelo de hiperfragmentación informativa (Fragmentación y Contraste Global), se definen cuatro posibles gradaciones en la aplicación conjunta de estos factores:

\begin{tabular}{|c|l|l|l|}
\hline Estímulo & \multicolumn{1}{|c|}{ Descripción } & $\begin{array}{c}\text { Fragmentación } \\
\text { (Cantidad) }\end{array}$ & \multicolumn{1}{|c|}{$\begin{array}{c}\text { Contraste } \\
\text { Global }\end{array}$} \\
\hline E1 & Contraste global y Fragmentación bajos & 10 elementos & 0,12 \\
\hline E2 & Contraste Global y Fragmentación medio-bajos & 14 elementos & 0,38 \\
\hline E3 & Contraste Global y Fragmentación medio-altos & 26 elementos & 0,52 \\
\hline E4 & Contraste Global y Fragmentación altos & 37 elementos & 0,61 \\
\hline
\end{tabular}

Tabla 10: Descripción de los cuatro reactivos y sus niveles de Fragmentación y Contraste (Global)

En el diseño de reactivos, se prestó especial atención a los siguientes condicionantes para evitar contaminar los resultados finales:

- Respeto escrupuloso a un mismo contenido textual.

- Evitar la redundancia de información.

- Adaptación a una estructura modular de 8x20 módulos (imprescindible para la medición de la Posición).

- Prioridad de maximizar la variable independiente para la mejor evaluación de las categorías.

- Respeto a los cánones y principios fundamentales del diseño periodístico. 

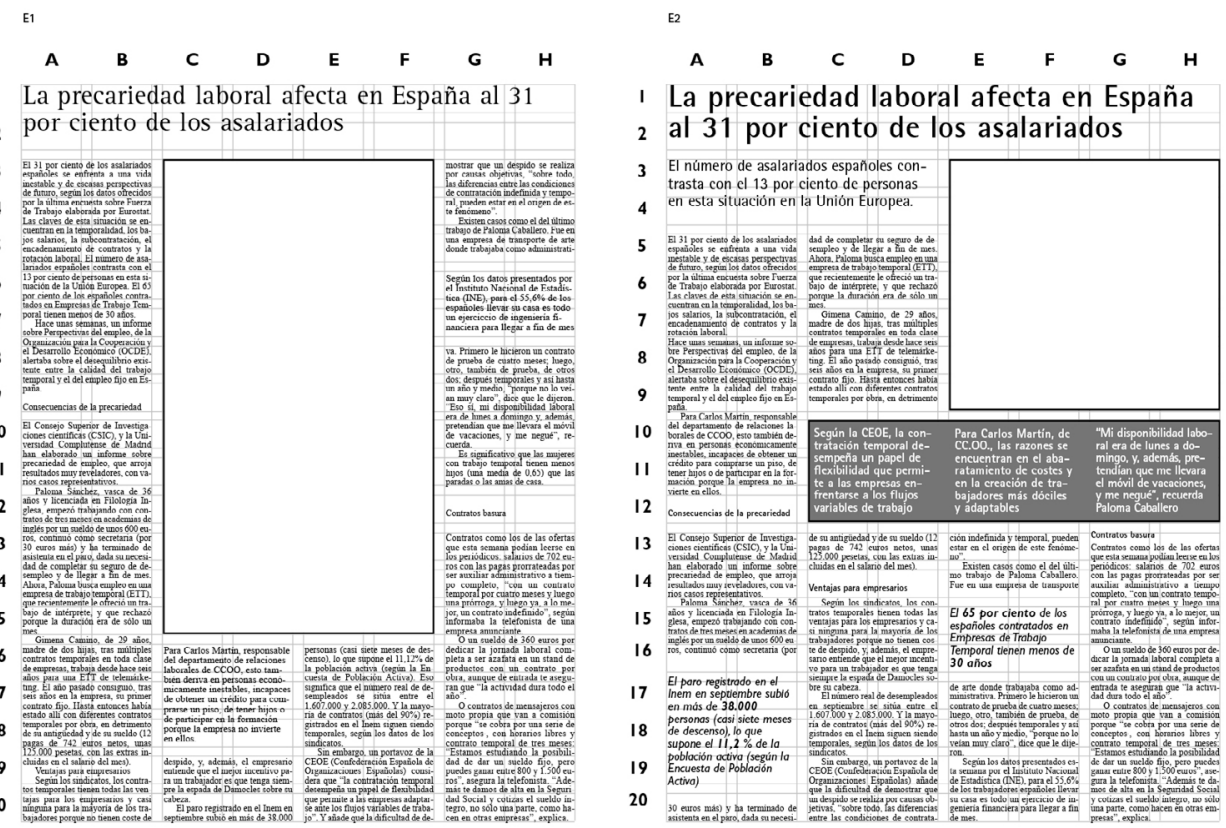

E3

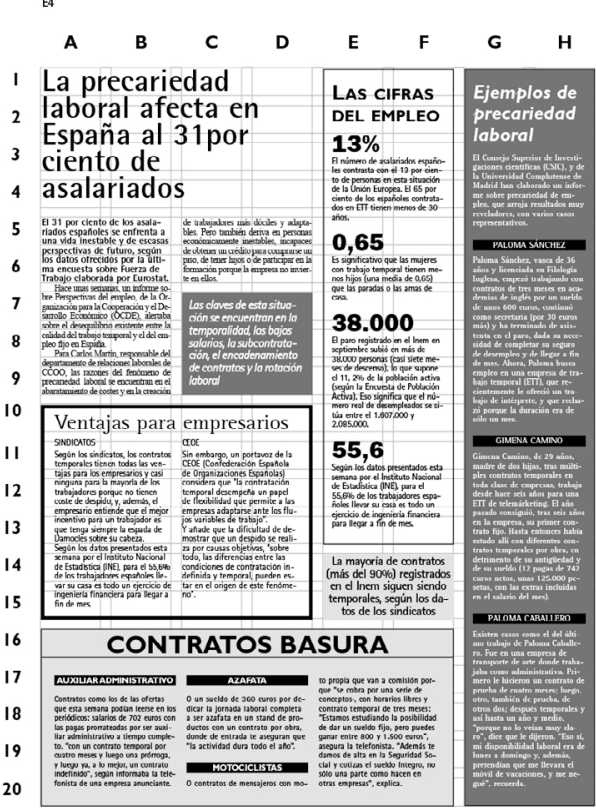

Figura 4: Representación de los cuatro estímulos de la investigación con la retícula empleada 


\subsubsection{Diseño del instrumento de recogida de datos}

Esta herramienta consistió en un cuestionario de reconocimiento sobre la información presente en los estímulos, constituido por un total de 18 preguntas vinculadas al contenido informativo de las páginas. Para poder responder eficazmente a la variable de focalización y a la incidencia de las categorías visuales, el proceso de construcción comprendió los siguientes pasos:

- Identificación de cada una de las preguntas del test con su elemento correspondiente en la página.

- Evaluación de los atributos formales de cada uno de estos elementos, según los diferentes valores de las categorías visuales que conforman la variable independiente.

- Valoración de los resultados obtenidos en cada elemento, agrupación según los diferentes niveles de las distintas categorías visuales y comparación final.

Mediante este procedimiento, es posible evaluar el rendimiento del sujeto en la página, en función de las propiedades formales de cada elemento individualizado (correspondientes a los diferentes niveles de las categorías visuales). Así, en cada uno de los reactivos, la información está incorporada en diferentes unidades formales, que, a su vez, registran atributos de Posición, Tamaño y Aspecto desiguales, con el fin de observar cuáles son, de estos, los que condicionan de forma más decisiva la lectura, el procesamiento y el recuerdo de la información presente en cada una de las páginas (constituidas por gradaciones distintas de Fragmentación y Contraste Global). 

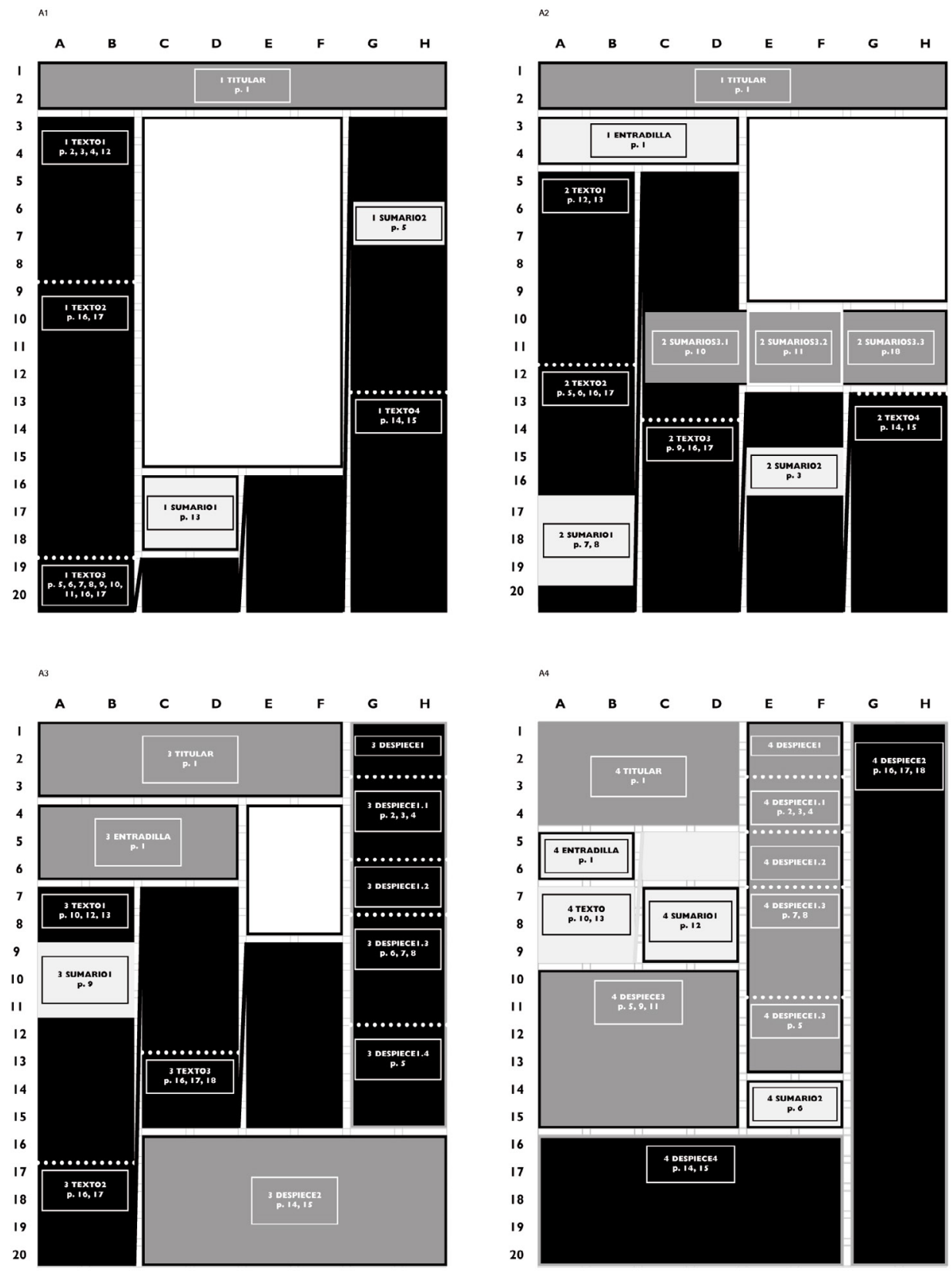

Figura 5: Relación de los elementos redaccionales de la página con los items del cuestionario 


\subsubsection{Definición de la muestra}

La investigación contó con un total de los 274 estudiantes universitarios como sujetos experimentales de la investigación, divididos en cuatro grupos para poder asignar a cada uno de ellos un estímulo diferente. La edad de estos sujetos oscila entre los 18 y los 24 años, con un claro predominio de aquellos situados en la franja de los 20 y los 21 años 9

\subsubsection{Exposición y presentación de estímulos}

Tras unas breves instrucciones (con las que, en todo momento, se buscó insistir en la necesidad de respetar, en la medida de lo posible, las conductas cotidianas de lectura y ocultar los objetivos finales de la investigación), se procedió a la lectura de las páginas y a la cumplimentación del cuestionario por parte de los sujetos. El tiempo de exposición a los reactivos fue limitado, con la intención primordial de dificultar la lectura completa de la página y, así, de atender al objetivo de focalización mediante la obligada selección de determinados items en estas condiciones.

\subsubsection{Evaluación de las respuestas de los sujetos}

A partir de los resultados del cuestionario, se evaluaron específicamente dos factores:

- La cantidad de respuestas correctas obtenidas, por una parte (que permite una orientación sobre el grado de comprensión de la información, globalmente, de la página).

- El tipo de respuestas correctas (que, de esta manera, mediante la observación de los elementos priorizados por el sujeto, pretende una aproximación a sus preferencias y a la focalización visual en torno a las categorías visuales citadas, en función de los valores de Fragmentación y Contraste Global).

\subsubsection{Análisis de los resultados}

Se comprueba en este paso si existe o no correlación entre el planteamiento formal y el comportamiento del sujeto hacia la página. Los resultados obteni- 
dos se evaluaron a partir de las siguientes cuatro estrategias:

1. Un análisis intra-página enfocado a observar la repercusión de las categorías visuales dentro de cada uno de los cuatro estímulos, definidos por gradaciones diferentes de Fragmentación y Contraste Global. Se mide cómo responde el lector, en cada tipo de estímulo, a los elementos informativos, previamente descritos a partir de sus cualidades de Tamaño, Aspecto, Contraste Individual y Posición.

2. Un análisis inter-página consistente en contrastar directamente los resultados obtenidos por las categorías visuales en los cuatro reactivos diseñados. Se trata de observar cómo actúan las categorías visuales en los estímulos y, al mismo tiempo, cómo los diferentes niveles de Fragmentación y Contraste de cada página pueden incidir en su repercusión.

3. Un análisis inter-página, orientado a comprobar cómo afecta el diseño (las categorías visuales) a un mismo tipo de información (las 18 preguntas del cuestionario).

4. Un análisis inter-página dirigido a comparar el volumen total de información adquirido en cada estímulo (equivalente a la comprensión global).

Para la comparación de medias de estas dos últimas, se ha recurrido a la ANOVA, tomando como factor independiente el "modelo de página" y, como variables dependientes, cada una de las preguntas individuales de la prueba de memoria explícita (en el análisis inter-página de estas cuestiones) y la suma de las respuestas totales correctas del sujeto (en el caso de la comprensión global). Para las comparaciones múltiples, de cara a evaluar el contraste individual de cada estímulo, se ha realizado la prueba de SCHEFFÉ, mediante la que se consideran significativos los resultados inferiores a 0,05. 


\section{Resultados}

\subsection{Resultados intra-página}

Este primer estudio, que pretende evaluar el comportamiento del lector en cada uno de los reactivos, arroja los siguientes datos:

- En los estímulos con menos vías de acceso alternativas a la lectura lineal (E1), las decisiones del lector se subordinan principalmente a la categoría de Posición.

- En los estímulos con valores medios de Fragmentación y Contraste Global (E2 y E3), son las variables de Tamaño y Contraste las que prevalecen fundamentalmente en la atención selectiva del lector. Por tanto, la posibilidad de ofrecer un número moderado de alternativas de selección al receptor actúa de forma decisiva en los mecanismos atencionales, que tienden a priorizar los elementos más breves y con un Aspecto más novedoso (es decir, con un mayor Contraste Individual en la página).

- En los niveles superiores de inestabilidad y profusión compositiva (E4), se produce un consenso en la preferencia por los elementos con un Contraste Individual acentuado de forma extrema.

- Mientras que en las páginas con un menor número de elementos y una homogeneidad formal superior tiende a observarse una mayor uniformidad en el comportamiento de lectura del sujeto, a medida que aumenta el número de unidades formales en la página y las posibilidades de acceso a la información disponible son mayores, se incrementa la variabilidad en la conducta de los sujetos. 

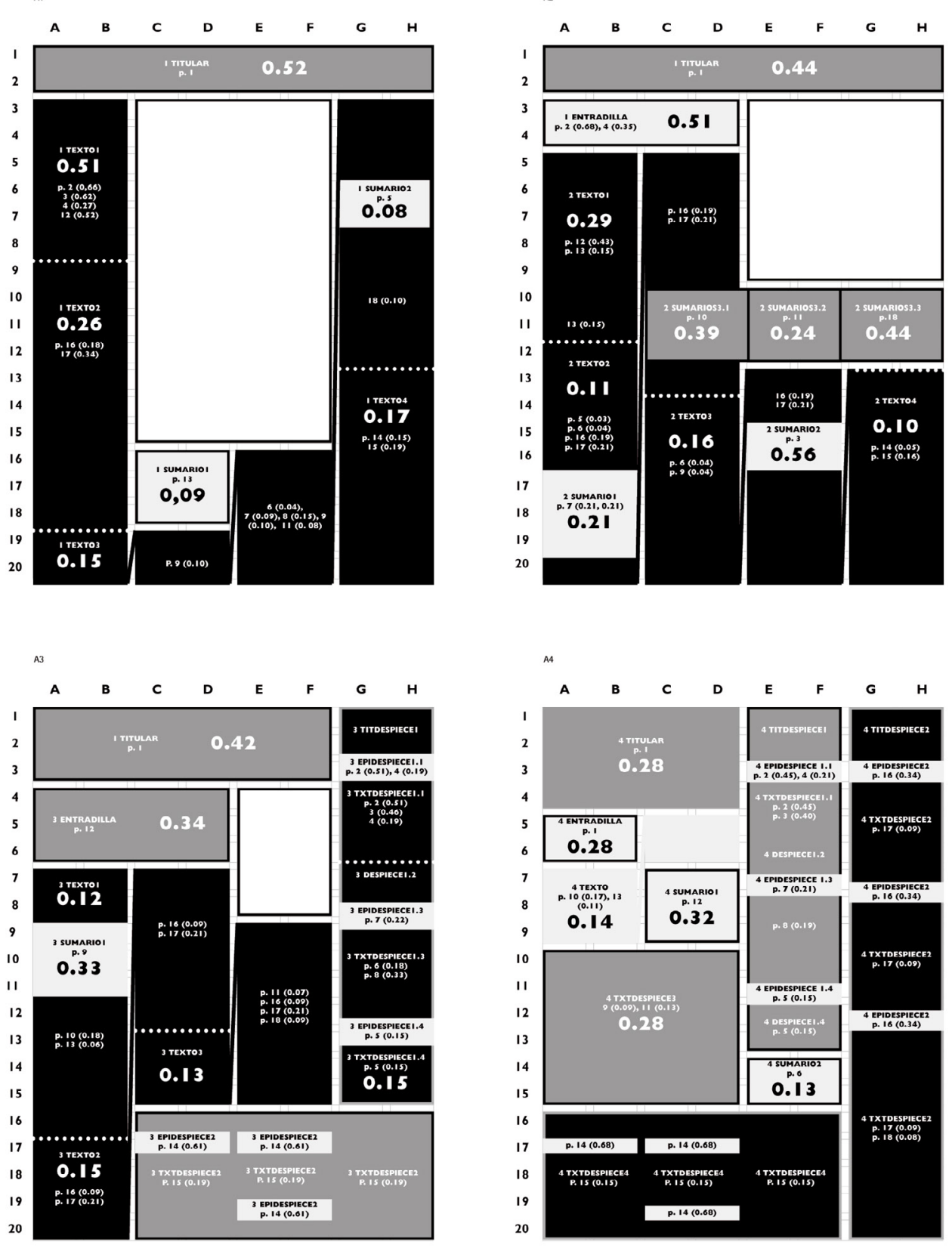

Figura 6: Esquema visual del rendimiento del sujeto en el procesamiento de los elementos de los cuatro estímulos 


\subsection{Resultados inter-página}

\subsubsection{Según categorias visuales}

En relación a la relevancia de las categorías visuales en la conducta del lector, los resultados más importantes se enumeran a continuación:

- La elevada repercusión de la categoría visual de Contraste Individual, fundamentalmente. Generalmente los sujetos apuestan por la lectura de aquellos estímulos visuales que, dentro de la página, son portadores de un menor Tamaño y, sobre todo, de una diferenciación formal mayor.

- La potenciación que se establece a través de la participación simultánea de las categorías de Aspecto, Tamaño (y Contraste Individual) y Posición. Esta última, como es obvio, incide especialmente cuando el planteamiento compositivo exige una lectura lineal de la información.

- La relevancia del grado de Fragmentación y Contraste Global de la página, que multiplica o atenúa la acción de las categorías visuales y condiciona la intensidad de la respuesta del individuo hacia estas. Puede argumentarse, pues, que los valores de las diferentes categorías visuales tratadas y su repercusión son relativos, en función de las propiedades visuales de los restantes elementos que integran la página.
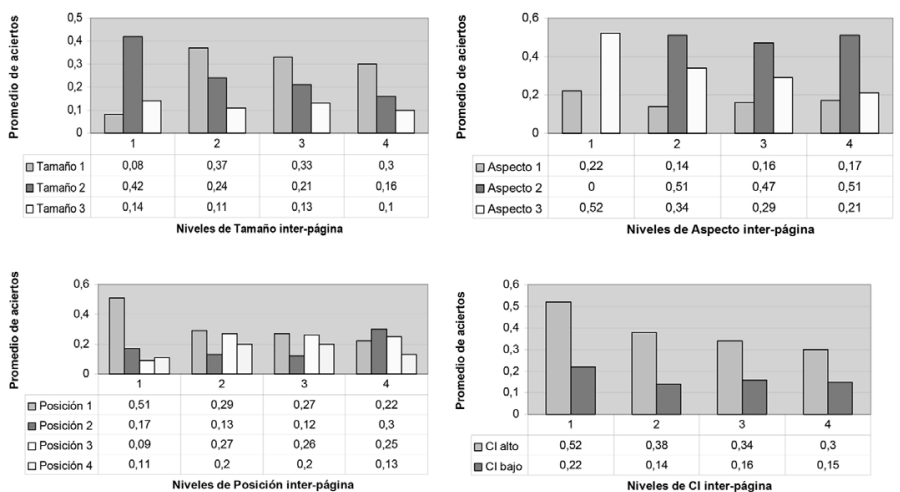

Figura 7: Comparación de los diferentes niveles de las categorías visuales en los diferentes estímulos 


\subsubsection{Preguntas individuales}

Después de la aplicación del procedimiento ANOVA y la prueba de Scheffé a cada una de las 18 preguntas del cuestionario, son un total de 10 items los que obtienen diferencias significativas de recuerdo mediante la asignación a sus correspondientes elementos de distintas categorías visuales en los cuatro estímulos. Junto a estos, se observaron tendencias positivas en 3 cuestiones, mientras que las 5 restantes no registraron diferencias aparentes ${ }^{10}$.

\subsubsection{Recuerdo global de la información}

Interpretando el recuerdo desde la perspectiva cuantitativa o total, se produce una elevada similitud, que parece justificar que, en pruebas efectuadas en laboratorio, y con claves temporales e instrucciones muy determinadas, la intensidad de la lectura y el procesamiento de la información son muy similares en los sujetos, independientemente de las condiciones globales de Fragmentación y Contraste.

Este hecho se aprecia en los similares resultados que se obtienen en el conjunto total de respuestas correctas obtenidas por parte del sujeto en el cuestionario de memoria explícita, que actúa como un índice de la cantidad total de información aprehendida; es decir, el conjunto de información retenida resulta muy similar en las cuatro variaciones de Fragmentación y Contraste.

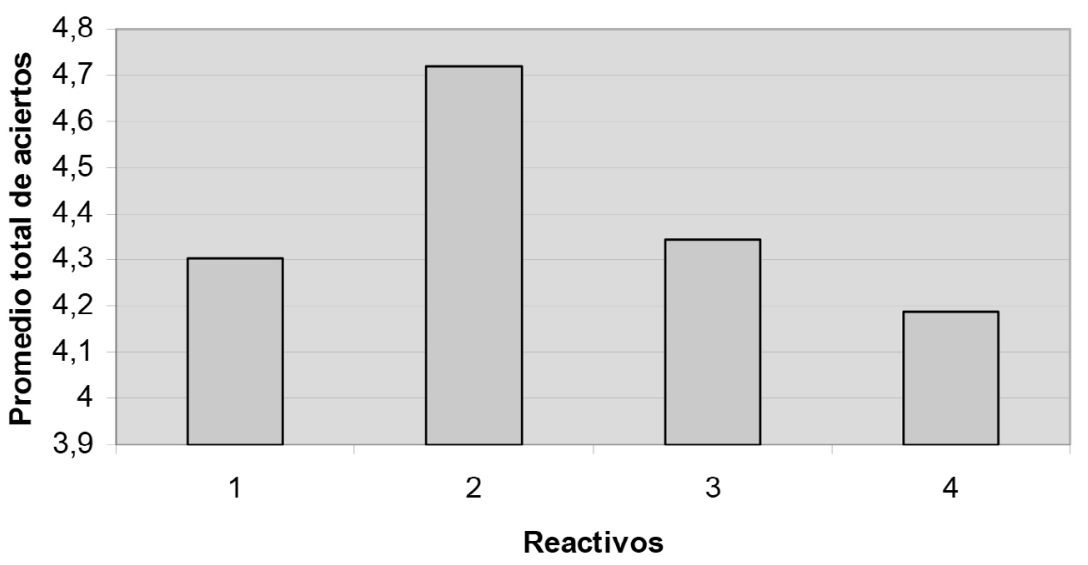

Figura 8: Representación gráfica del rendimiento total del sujeto (media de respuestas correctas) en los cuatro estímulos 


\begin{tabular}{|c|c|c|c|c|c|}
\hline & Suma de cuadrados & gl & Media cuadrática & F & Sig. \\
\hline Inter-grupos & 10,986 & 3 & 3,662 &, 803 &, 493 \\
\hline Intra-grupos & 1231,047 & 270 & 4,559 & & \\
\hline Total & 1242,033 & 273 & & & \\
\hline
\end{tabular}

Tabla 11: Evaluación de la significación de la suma de respuestas correctas mediante la prueba ANOVA

\begin{tabular}{|c|c|c|c|c|}
\hline & & Diferencia de medias (I-J) & Error típico & Sig. \\
\hline $\begin{array}{c}\text { (I) modelo } \\
\text { de página }\end{array}$ & $\begin{array}{c}\text { (J) modelo } \\
\text { de página }\end{array}$ & & & \\
\hline E1 & E2 &,- 4162 &, 34425 &, 691 \\
\hline & E3 &,- 0395 &, 35463 & 1,000 \\
\hline & E4 &, 1151 &, 37913 &, 993 \\
\hline E2 & E1 &, 4162 &, 34425 &, 691 \\
\hline & E3 &, 3767 &, 35895 &, 777 \\
\hline & E4 &, 5313 &, 38317 &, 589 \\
\hline E3 & E1 &, 0395 &, 35463 & 1,000 \\
\hline & E2 &,- 3767 &, 35895 &, 777 \\
\hline & E4 &, 1546 &, 39253 &, 984 \\
\hline E4 & E1 &,- 1151 &, 37913 &, 993 \\
\hline & E2 &,- 5313 &, 38317 &, 589 \\
\hline & E3 &,- 1546 &, 39253 &, 984 \\
\hline
\end{tabular}

Tabla 12: Comparaciones múltiples de la significación entre estímulos a través de la prueba de Scheffé

\section{Discusión}

Tras la observación y análisis de los resultados obtenidos empíricamente en la investigación, este capítulo quiere ofrecer, a modo de conclusión, una serie de consideraciones finales respecto a los objetivos e hipótesis formulados en el origen del estudio:

- El Diseño Periodístico Impreso repercute en la respuesta del receptor ante la página impresa. Se observan algunas constantes evidentes e índi- 
ces de preferencia comunes en determinados resultados individuales de las pruebas inter-página e intra-página que revelan que el componente formal de la página impresa es un elemento importante en la recepción de la información por parte del receptor.

- La hiperfragmentación informativa repercute en los mecanismos cognitivos del sujeto y condiciona su conducta ante la página impresa.

- El Diseño Periodístico Impreso, a través de la Fragmentación y el Contraste, no permite observar variaciones significativas en la comprensión global del sujeto sobre la información de la página impresa. Puede afirmarse que la comprensión, interpretada desde mecanismos como la atención sostenida o la concentración, y evaluada a través del volumen de información total retenida, resulta difícil de evaluar en las condiciones mencionadas. Los estrictos ajustes de tiempo o la influencia de las orientaciones previas pueden suponer algunas restricciones que deberán tenerse ser consideradas en futuras experiencias de investigación similares.

- La progresiva aplicación de Fragmentación y Contraste Global y la resultante creación de un mayor número de posibles vías de lectura de la información generan una creciente heterogeneidad en el comportamiento de consumo informativo de los diferentes sujetos.

- El Diseño Periodístico Impreso, a través de la modificación y aplicación de las cuatro categorías visuales básicas, asociadas a diferentes elementos, determina el comportamiento del sujeto en lo relativo a su preferencia, atención selectiva y recorrido visual de la página.

- En general, con respecto al planteamiento global de la página, los sujetos seleccionan aquellos elementos informativos más breves (Tamaño) y con una diferenciación formal mayor (Aspecto), y por tanto, con un Contraste Individual elevado, categoría que resulta de especial relevancia para el estudio de la focalización en el Diseño Periodístico Impreso. 
100 | Fernando Suárez Carballo, Juan Ramón Martín San Román y Javier Nó Sánchez

- Los valores globales de hiperfragmentación, es decir, de los atributos de Cantidad o Fragmentación y Contraste Global de la página impresa, condicionan la actividad y el efecto de las cuatro categorías visuales básicas aplicadas a los elementos informativos.

Asimismo, se hace preciso constatar, de forma muy sucinta, una serie de limitaciones que deberían tenerse en cuenta en futuras líneas de investigación, y que se enumeran a continuación a modo de nuevos retos:

- Impulsar la consideración multidisciplinar, necesaria para un análisis exhaustivo de la eficacia del diseño gráfico, mediante una mayor implicación de otros ámbitos científicos (psicología, sociología o filología).

- Revisar la variable independiente, maximizando la diferencia entre estímulos, verificando la operacionalización de las categorías propuestas (la ponderación de los distintos atributos de Aspecto, por ejemplo) 0 neutralizando el ruido causado por la injerencia de algunos factores imprevistos, como la excesiva complejidad del contenido.

- Superar las tradicionales dificultades que plantea la medición en laboratorio y acercar el experimento a condiciones de lectura más naturales.

- Contrastar los resultados de las tareas de recuerdo con nuevos instrumentos metodológicos (entrevistas, eye tracker).

- Ampliar el exclusivo tratamiento de los elementos tipográficos a un mayor número de recursos gráficos, como la fotografía y la infografía, y aplicar la herramienta metodológica en nuevos medios y soportes (como páginas web, tablets o smartphones). 


\section{Notas}

[1] El estudio busca subrayar el apellido "impreso" para diferenciarlo de otro tipo de productos informativos, como páginas web o publicaciones en tablets o smartphones. Aunque muchas de las premisas del estudio pueden ser extrapolables a estos, no están en ningún momento contrastadas empíricamente.

[2] Es necesario precisar que la focalización visual, concebida como tal, no implica necesariamente el procesamiento semántico; sin embargo, en el modelo actual, ambos términos están necesariamente vinculados.

[3] Hay que hacer hincapié en que la investigación se centra exclusivamente en los atributos plásticos de los elementos tipográficos, según la clasificación de West (1991). Posteriores estudios deberían completarse con otros elementos de diferente iconicidad (fotografía, infografía) para un análisis más completo de eficacia del diseño en la página impresa.

[4] Para poder efectuar un análisis pormenorizado de la página a partir de las citadas categorías visuales, se hace necesaria una mayor disección de determinados elementos (como el cuerpo de texto o los despieces). Este hecho redunda en un juicio más preciso de las características de las variables y su eficacia.

[5] No debe confundirse el Tamaño, o número de módulos total aplicado a las unidades formales diferenciadas de la página, con el cuerpo tipográfico, subcategoría asociada a las microformas que contribuye a definir la variable de Aspecto.

[6] Las variables independientes son un concepto difícil de sistematizar de forma universal, dado que sufren una importante dependencia de un sinnúmero de factores, tales como la dimensión de la mancha o las características formales de los elementos integrantes, criterios que condicionan los valores que se les deben atribuir. Por ello, y debido a la inexistencia de literatura que determine a qué magnitudes debe ajustarse el trabajo, la presente investigación propone su propio modelo, con parámetros creados a partir de márgenes suficientemente amplios y flexibles como para poder constatar las diferencias existentes en cada página. Para futuros estudios de este tipo, sin embargo, sería interesante definir una fórmula susceptible de validar de forma estable los valores de estas variables.

[7] Esta circunstancia es especialmente relevante en elementos redaccionales como el texto común o los despieces, que, a pesar de conformar formas íntegras en sí mismas, poseen varias partes diferenciadas.

[8] La amplia diversidad de Tamaños de los diferentes elementos y la elevada complejidad para determinar su situación exclusiva en cada uno los cuadrantes influye en la dificultad para definir la ubicación exacta de algunos de ellos. Por ello, en caso de no poder establecer una localización estricta, se tomará como referencia la ubicación de la mayor parte del elemento o, en caso de conflicto, el comienzo de este.

DOI: ri14.v12i1.627 | ISSN: 1697-8293 | Año 2014 Volumen 12 Nº 1 | ICONO14 
[9] Es natural que este hecho pueda constituir un sesgo en la universalidad de la muestra; no obstante, la legitimidad de la propuesta se justifica ante la inexistencia de indicios claros de que perfiles diferentes de participantes pudieran modificar de forma decisiva los resultados obtenidos, por lo que las características de estos sujetos se establecieron como válidas para argumentar su representatividad. En todo caso, pueden tomarse en consideración estos datos para juzgar los resultados.

[10] Es preciso subrayar una cierta relevancia del tipo de contenido en la evaluación de los atributos formales. Una de las principales limitaciones de la investigación, que será tenida en cuenta para futuros estudios, está ligada a la excesiva complejidad de la información representada en los estímulos. Este hecho ha podido motivar que, pese a su selección, algunos elementos no hayan podido ser memorizados. Es preciso, por tanto, extremar su simplicidad para minimizar su interferencia en los resultados.

\section{Referencias}

AIMC (2013): 15 ancuesta a Usuarios de Internet, Navegantes en la Red. Disponible en: http://www.aimc.es/-Navegantes-en-la-Red-.html [20/03/2013].

Álvarez Marcos, J. (1999). Tecnologías para la información periodística. Sevilla: Mad.

Aparici, R., García Matilla, A. y Valdivia Santiago, M. (1992). La imagen. Madrid: UNED.

Armentia Vizuete, J. I., Eletxegaray, J. y Pérez, J.C. (2001). Diseño y periodismo electrónico. Guipúzcoa: Universidad del País Vasco.

Botella, J. (1999). "El estudio experimental de la atención". En Munar, E., Roselló, J. y Sánchez Cabaco, A.: Atención y percepción, pp. 63-98. Madrid: Alianza Editorial.

Casasús, J.M. (1995). "Renovación tecnológica y diseño de un periódico nacional". Comunicación y estudios Universitarios, 5. Valencia: CEU.

Contreras, F. y San Nicolás, C. (2001). Diseño gráfico, creatividad y comunicación. Madrid: Blur Ediciones.

Costa, J. (1998). La esquemática. Visualizar la información. Barcelona: Paidós Ibérica.

Costa Sánchez, C. (2013): Prensa en el Smartphone. Modelos aplicados en los diarios españoles y necesidades de desarrollo, Icono 14, volumen 11 (2), pp. 07-30. doi: 10.7195/ri14.v11i2.591.

Crespo, A. (1999). “Organización perceptual y reconocimiento visual del objeto". En 
Munar, E., Roselló, J. y Sánchez-Cabaco, A.: Atención y percepción, pp. 339378. Madrid: Alianza Editorial.

Dondis, D. A. (1976). La sintaxis de la imagen: introducción al alfabeto visual. $13^{\mathrm{a}}$ ed. Barcelona: Gustavo Gili.

Elosúa, M.R. (2000). Procesos de la comprensión, memoria y aprendizaje de textos. Madrid: Sanz y Torres.

Groupe $\mu$ (1993). Tratado del signo visual. Madrid: Cátedra.

Gubern, R. (1992). La imagen opulenta. Exploración de la iconosfera contemporánea. Barcelona: Gustavo Gili.

Gutiérrez, F., Elosúa, M.R., García Madruga, J.A., Gárate, M. y Luque, J.L. (1999).

"Memoria operativa y comprensión lectora". En García Madruga, J.A., Elosúa,

M.R., Gutiérrez, F., Luque, J.L y Gárate, M.: Comprensión lectora y memoria operativa. Aspectos evolutivos e instruccionales, pp. 15-32. Barcelona: Paidós.

Kahnemann, D. (1997). Atención y esfuerzo. Madrid: Biblioteca nueva.

Kohler, W. (1972). Psicología de la forma, su tarea y últimas experiencias. Madrid: Biblioteca nueva.

Küpper, N. (1990). Grabación de la mirada. Investigación del comportamiento del lector al leer periódicos. Extraído el 7/06/2004 http://calendardesign.de/ leseforschung/Grabaciondelamirada.pdf.

Lallana, F. (2000). Tipografia y diseño. Madrid: Síntesis.

López García, X. (2000). “El modelo local de la prensa gallega redefine sus estrategias para competir en la nueva era" [versión electrónica], Zer, 9.

Extraído el 7/08/2004 de http://www.ehu.es/zer/zer9/9lopez.html. Moles, A. (1991). La imagen. Comunicación funcional. México D.F.: Trillas. Pérez Cuadrado:y González Díez, L. (2001). Principios básicos sobre Diseño Periodistico. Madrid: Editorial Universitas.

Puente Ferreras, A. (1998). Cognición y aprendizaje. Fundamentos psicológicos. Madrid: Pirámide.

Rom, J. (2002). Els fonaments del Disseny Gráfic. Barcelona: Trípodos.

Roselló, J. (1997). Psicología de la atención. Introducción al estudio del mecanismo atencional. Madrid: Pirámide.

Suárez Carballo, F. (2008). Fundamentos del diseño periodístico. Claves para interpretar el lenguaje visual del diario. Navarra: Eunsa.

Tena, D. (1999). “Una propuesta metodológica en torno a la investigación científica 
104 | Fernando Suárez Carballo, Juan Ramón Martín San Román y Javier Nó Sánchez

sobre los medios impresos: el estado estético", Zer, 6, pp. 199-218. Guipúzcoa: UPV.

Vega, M. de (1997). Introducción a la Psicología Cognitiva. Madrid: Alambra. Villafañe, J. y Mínguez, N. (2000). Principios de Teoría General de la Imagen. Madrid: Pirámide.

West, S. (1991). Cuestión de estilo. Los enfoques tradicional y moderno en maquetación y tipografia. Madrid: Ack Publish. 